\title{
A análise dos metadados dos artigos dos periódicos vinculados ao Portal de Periódicos UFMG
}

\author{
OLIVEIRA, Carla Cristina Vieira de ${ }^{1 *}$ \\ OLIVEIRA, Bruno Fernandes Magalhães de $\mathrm{e}^{2 * *}$ \\ SOUZA, Terezinha de Fátima Carvalho $\mathrm{de}^{3 * * *}$ \\ 1,2,3 Uuniversidade Federal de Minas Gerais - Brasil \\ ORCID ID: https://orcid.org/0000-0002-0385-535X* \\ ORCID ID: https://orcid.org/0000-0002-1183-7864** \\ ORCID ID: https://orcid.org/0000-0001-5383-6061**
}

\begin{abstract}
Resumo
Com a formalização da Política de Periódicos Científicos na Universidade Federal de Minas Gerais (UFMG) em setembro de 2019 via resolução interna da universidade, o Portal de Periódicos UFMG passou a atribuir o Digital Object Identifier (DOI) às publicações após a avaliação dos metadados dos artigos. O presente trabalho objetiva registrar a experiência, as dificuldades e os benefícios observados no processo de correção e orientação dos editores com vistas à qualidade dos registros apresentados nas revistas. A relevância deste procedimento justifica-se na melhoria da recuperação dos metadados como título, autoria, resumo, palavras-chave, entre outros que no universo do acesso aberto e dos sistemas interoperáveis é essencial para a visibilidade das publicações.
\end{abstract}

Palavras-chave: Metadados. Acesso livre. Visibilidade de artigo científico.

\begin{abstract}
Analysis of the metadata of articles in journals linked to the UFMG Journal Portal Abstract

With the formalization of the scientific journals policy at Federal University of Minas Gerais (UFMG) in September 2019 via university internal resolution, Portal Periódicos UFMG started to assign the Digital Object Identifier (DOI) to publications after the evaluation of the articles' metadata. This paper aims to record the experience, difficulties and benefits observed in the process of correction and guidance of editors with a view to the quality of the records presented in the journals. The relevance of this procedure is justified in improving the recovery of key fields of metadata such as title, authorship, abstract / abstract, keywords / keywords, languages among others that in the universe of open access and interoperable systems is essential for the visibility of publications.
\end{abstract}

Keywords: Metadata. Open access. Scientific article visibility.

\section{Análisis de los metadatos de artículos en revistas vinculadas al Portal de Revistas de la} UFMG

\section{Resumen}

Con la formalización de la política de revistas científicas en la Universidad Federal de Minas Gerais (UFMG) en septiembre de 2019 mediante resolución interna de la universidad, Portal Periódicos UFMG comenzó a asignar el Identificador de Objeto Digital (DOI) a las publicaciones luego de la evaluación de los metadatos de los artículos. Este trabajo tiene como objetivo registrar la experiencia, las dificultades y beneficios observados en el proceso de corrección y orientación de los editores con miras a la calidad e los registros presentados en las revistas. La relevancia de este procedimiento se justifica en mejorar la recuperación de campos clave de metadatos como título, autoría, resumen / resumen, palabras clave / palabras clave, idiomas entre otros que en el universo de acceso abierto y sistemas interoperables es fundamental para la visibilidad de publicaciones.

Palabras Clave: Metadatos. Acceso abierto. Visibilidad de artículos científicos. 


\section{ABEC Meeting Live 2020}

\section{Introdução}

Os periódicos científicos são fundamentais para a disseminação dos resultados das pesquisas científicas e disseminação do conhecimento. Foi através do movimento de Acesso Aberto, que surgiu na década de 90 em oposição aos aumentos significativos nas assinaturas dos periódicos científicos, que o processo de comunicação científica com o auxílio das tecnologias da informação e comunicação (TIC’s) tornou mais ágil e acessível a divulgação dos periódicos em formato eletrônico (BANDEIRA, 2017). O processo de comunicação científica com o auxílio das tecnologias da informação e comunicação (TIC’s) tornou mais ágil e acessível a divulgação dos periódicos em formato eletrônico (BANDEIRA, 2017). O acesso às revistas científicas ocorre por meio de computadores ou até mesmo celulares, com o dinamismo comum das TIC`s e de forma gratuita. O sistema de gerenciamento eletrônico, Open Journal Systems (OJS), software livre, permitiu a difusão dos periódicos em formato eletrônico. Destaca-se como uma das vantagens deste sistema a transparência de todo o processo editorial (MELO; MANDUCA; SANTOS, 2019).

Entretanto, na medida em que as TIC's tornaram mais ágil o processo de comunicação científica, também contribuíram para o aumento significativo de informação disponível, o que tem exigido contínuos esforços para identificar e organizar os milhares de documentos publicados. Dentre estes esforços, destaca-se o Digital Object Identifier (DOI) como um identificador de documentos em redes digitais que permite a identificação da publicação de forma única e persistente no ambiente eletrônico. De acordo com Brito et al. (2015, p. 8), "atualmente, [o DOI] tem sido muito adotado na Internet, devido, principalmente, às necessidades de padronização e preservação das informações contidas nesse ambiente". Para atender plenamente tais necessidades, metadados precisos, consistentes e confiáveis permitem uma recuperação da informação eficaz, com a localização de artigos relevantes de forma rápida e fácil (PALAVITSINIS; MANOUSELIS; SANCHEZ-ALONSO, 2014). Este trabalho objetiva compartilhar a experiência atual com o serviço de atribuição de DOI e revisão dos metadados dos artigos das revistas que pertencem ao Portal de Periódicos UFMG.

A qualidade dos metadados interfere na visibilidade do manuscrito em um universo em que muitos sistemas são interoperáveis, ou seja, comunicam-se entre si. Assim, o preenchimento adequado dos metadados pode influenciar no alcance do artigo e, consequentemente, do periódico. Com a Iniciativa dos Arquivos Abertos (OAI), instituiu-se o padrão Dublin Core, utilizado para descrição e representação de recursos eletrônicos, assim como os protocolos para a interoperabilidade como o Open Archives Initiative Protocol for Metadata Harvesting (OAI-PHM) protocolo de internet usado para coleta de metadados. (BENTANCOURT; ROCHA, 2007). Assim, 


\section{ABEC Meeting Live 2020}

com a editoração eletrônica, o suporte online permite novas estratégias de busca que aumentam a visibilidade das publicações. De acordo com Gruszynski e Golin (2007), a visibilidade refere-se à capacidade de ser acessado em bases de dados e índices. Tornar um artigo visível é possibilitar a sua ampla divulgação. Os metadados colaboram para o aumento da visibilidade, pois descrevem por categorias, pontos importantes dos artigos que devem ser inseridos corretamente no sistema e em consonância com os padrões de normalização adotados pelo periódico.

Aprimorar a visibilidade dos periódicos vinculados ao Portal de Periódicos UFMG, lançado em 2015 e instituído politicamente em 2019 é o maior objetivo da Resolução 08/2019 que visa aperfeiçoar a qualidade e a visibilidade das publicações científicas da universidade (UFMG, 2019). Junto a esse reconhecimento institucional, obteve-se o recurso da Pró-Reitoria de Pesquisa (PRPq) para atribuição do DOI via edital, aos periódicos que atendessem aos requisitos básicos da política. Os artigos das revistas contempladas no edital recebem o DOI após a conferência dos metadados no OJS pela equipe de bibliotecários do portal. Assim que os editores submetem uma proposta ao edital para atribuição do DOI, a equipe de bibliotecários avalia os metadados da revista e, em especial dos artigos, para elaborar e apresentar ao editor um relatório com as inconsistências e falhas encontradas e a orientação para a sua correção

Acredita-se que o procedimento de revisão dos metadados deve ser realizado pela equipe editorial dos periódicos de forma contínua, pois no fluxo natural da editoração científica, os primeiros metadados são preenchidos pelos autores no processo de submissão de seus artigos e podem neste processo ocorrer erros por desconhecimento ou de digitação, ou após a revisão dos artigos solicitada pelos revisores, não sendo os dados atualizados no OJS mantendo uma inconsistência com o artigo publicado. Sendo assim, torna-se fundamental que os editores revejam os metadados da submissão no OJS antes da publicação dos artigos. Atrelar a revisão dos metadados pelos bibliotecários antes da atribuição do DOI permitiu à equipe do Portal de Periódicos UFMG validar essa revisão dos editores com vistas a manter a qualidade dos metadados inseridos nos artigos.

\section{Metodologia}

Trata-se de uma pesquisa qualitativa que, através do estudo de caso, estratégia de pesquisa que envolve um método de abordagens específicas para coleta e análise de dados (YIN, 2001), analisou os relatórios de correção dos metadados dos artigos das revistas que submeteram proposta ao edital para atribuição do DOI. O instrumento de coleta de dados adotado foi a análise desses relatórios apresentados aos 23 editores que tiveram aprovação nos quesitos do edital. 


\section{ABEC Meeting Live 2020}

\section{Resultados e Discussão}

No período de aproximadamente um ano, 23 revistas submeteram proposta ao edital de atribuição do DOI e passaram pela análise de metadados. Dentre as inconsistências e falhas observadas neste período, destacam-se: dados incorretos na afiliação do autor, nos títulos e subtítulos, uso de pontuação inadequada no título, resumos e referências com textos descontínuos, discordância entre palavras-chave no PDF e no OJS, uso inapropriado do campo do subtítulo, nome do autor incompleto ou errado no OJS, erros no uso dos prefixos dos títulos no OJS, a presença de palavras-chave incorretas, a ordenação da autoria no OJS diferente do PDF dos artigos, erros de digitação, ausência de palavras-chave, títulos e referências incorretas, entre outros apontamentos.

\section{Considerações finais}

Infere-se que o procedimento de análise de metadados dos artigos dos periódicos científicos pela equipe do Portal de Periódicos tem colaborado para melhoria da visibilidade dos artigos e aprimorado a qualidade dos periódicos da UFMG. O processo de conferência de metadados é demorado, detalhado e árduo, tanto para os bibliotecários quanto para os editores, contudo, sua relevância é inquestionável para a melhoria da qualidade das publicações. A acolhida dos editores tem sido satisfatória e o retorno das correções também. Essa avaliação está associada à adesão ao Edital do DOI, item previsto na política de periódicos do Portal, o que ainda não está ocorrendo com todos os periódicos, impedindo que, no momento, se tenha controle da revisão de consistência dos metadados para todos aqueles periódicos que fazem parte do Portal. Esse é o desafio que a equipe se coloca: estender esse procedimento para todos os periódicos.

\section{Referências}

BANDEIRA, Pablo Matias. Movimento de Acesso Remoto no Brasil: contribuição do Instituto Brasileiro de Informação em Ciência e Tecnologia a partir da implementação do Sistema Eletrônico de Editoração de Revistas. Dissertação (Mestre em Ciência da Informação) Universidade Federal da Paraíba, João Pessoa, 2017. Disponível em: https://repositorio.ufpb.br/jspui/bitstream/tede/9702/2/ArquivoTotal.pdf . Acesso em: 25 ago. 2020.

BENTANCOURT, Silvia Maria Puentes; ROCHA, Rafael Port da. Metadados de qualidade e visibilidade na comunicação científica. Encontros Bibli: Revista Eletrônica de Biblioteconomia e Ciência da Informação, v. 17, n. esp., p. 82-101, 2012. DOI: 10.5007/15182924.2012v17nesp2p82

BRITO, Ronnie Fagundes de; SHINTAKU, Milton; SOARES, Suely de Brito Clemente; WEBER, Claudiane. Guia do Usuário do Digital Object Identifier. Brasília: Instituto Brasileiro de Informação em Ciência e Tecnologia, 2015. 63 p. 
GRUSZYNSKI, Ana Cláudia; GOLIN, Cida. Periódicos científicos eletrônicos e a visibilidade da ciência na web: estudo de caso na ufrgs. DataGramaZero, v. 8, n. 3, 2007. Disponível em: http://hdl.handle.net/20.500.11959/brapci/6078. Acesso em: 24 ago. 2020.

MELO, Paula Lorena Silva; MANDUCA, Marcelo; SANTOS, Elisama Nunes dos. A produção editorial de revistas científicas através do OJS na PUCPR: desafios iniciais da utilização do sistema e da gestão de periódicos. Ciência da Informação em Revista, Maceió, p. 37-47, 2019. Disponível em: https://www.seer.ufal.br/index.php/cir/article/view/6908 Acesso em: 24 ago. 2020.

PALAVITSINIS, Nikolaos; MANOUSELIS, Nikos; SANCHEZ-ALONSO, Salvador. Metadata quality in learning object repositories: a case study. The electronic library, v. 32, n.1, 2014, pp. 6282. DOI: http://dx.doi.org/10.1108/EL-12-2011-0175.

UNIVERSIDADE FEDERAL DE MINAS GERAIS. Conselho de Ensino, Pesquisa e Extensão. Resolução 08/2019, 19 de setembro de 2019. Estabelece a política de periódicos científicos da Universidade Federal de Minas Gerais (UFMG). Belo Horizonte, 2019. Disponível em: https://www.ufmg.br/periodicos/documentos/. Acesso em: 24 ago. 2020.

YIN, Roberto K. Estudo de caso: planejamento e métodos. 2. ed. Porto Alegre: Bookmam. 2001.

\title{
${ }^{1}$ Carla Cristina Vieira de Oliveira (Belo Horizonte, Minas Gerais, Brasil)
}

Doutora em Ciência da Informação. Bibliotecária do Portal de Periódicos da UFMG. Pró-reitoria de Pesquisa Contribuição de autoria: Escrita - Revisão

Lattes: http://lattes.cnpq.br/3996984941043786

E-mail: cvieirao@gmail.com

\author{
${ }^{2}$ Bruno Fernandes Magalhães de Oliveira (Belo Horizonte, Minas Gerais, Brasil) \\ Bibliotecário do Portal de Periódicos da UFMG. Pró-reitoria de Pesquisa. \\ Contribuição de autoria: Escrita - Revisão \\ Lattes: http://lattes.cnpq.br/1311495251849964 \\ E-mail: portalperiodicos@prpq.ufmg.br
}

\section{Terezinha de Fátima Carvalho de Souza (Belo Horizonte, Minas Gerais, Brasil)}

Doutora em Ciência da Informação. Professora Adjunto Escola de Ciência da Informação. Diretora da Escola de Ciência da Informação. Editora da revista Perspectivas em Ciência da Informação. Coordenadora do COGEPPE Comitê Gestor do Portal de Periódicos da UFMG.

Contribuição de autoria: Escrita - Revisão - Edição

Lattes: http http://lattes.cnpq.br/1770963488944541

E-mail: terezinha@eci.ufmg.br

Avaliador(a) responsável: Lia Machado Fiuza Fialho

\section{Como citar este artigo:}

OLIVEIRA, Carla Cristina Vieira de, OLIVEIRA, Bruno Fernandes Magalhães de, SOUZA, Terezinha de Fátima Carvalho de. A análise dos metadados dos artigos dos periódicos vinculados ao Portal de Periódicos UFMG. In: ABEC Meeting Live, 2020. Anais... São Paulo: Associação Brasileira de Editores Científicos, 2020. DOI: http://dx.doi.org/10.21452/abecmeeting2020.08 